\title{
Pediatric nasolacrimal duct obstruction a review of current management
}

\begin{abstract}
Purpose: Congenital nasolacrimal duct obstruction is a common condition that is treated conservatively. There are varying reports on when to consider intervention. The aim of this study is assess when intervention is performed in England on the National Health Service and to review the opinions of Oculoplastic surgeons in the United Kingdom.
\end{abstract}

Methods: A survey was sent by email to 130 oculoplastic surgeons with 10 closed questions on syringing and probing and dacryoscystorhinostomy in pediatric cases and responses were analysed. C25 and C27 National Health Service codes in England were looked at from the period of 2012-2016 which cover syringing and dacryocystorhinostomy and syringing and probing procedures respectively. Total admissions coded for these procedures were looked at covering age groups from 0 to 18 years.

Results: A mean of 1607 syringing and probing procedures during 2012-2016 periods with the most common age group was being those in the 1-4 year age group. A minority were performed in those aged less than 1 year. Oculoplastic surgeons would commonly consider syringing and probing in the 1-2 year age group consistent with current evidence. Dacryocystorhinostomy is most commonly performed in the 1-4 age group with the majority performed in the 1-14 age group overall. The highest number of revision dacryocystorhinostomy procedures were performed in the the 1-9 age group.

Conclusion: The majority of syringing and probing procedures were performed over the age of 1 year constant with current evidence. There are a substantial number of oculoplastic surgeons that would consider endonasal dacryocystorhinostomy in pediatric cases although the current preference is for an external approach. Revision dacryocystorhinotomy most commonly occurs in the 1-9 age group.
Volume 9 Issue 5 - 2019

\author{
Ahmad Aziz,' Vickie Lee,' Ahmed Alnahrawy,' \\ Yassir Abourayyah, ${ }^{2}$ Rajni Jain ${ }^{2}$ \\ 'Western Eye Hospital, UK \\ ${ }^{2}$ Moorfields Eye Hospital, UK
}

Correspondence: Ahmad Aziz, Western Eye Hospital, I53-173 Marylebone Rd, Marylebone, London NWI 5QH, UK, Emailahmad.aziz@nhs.net

Received: September 24, 2019 | Published: October 08, 2019

\section{Text}

\section{Introduction}

Congenital nasolacrimal duct obstruction is a condition that occurs commonly in infants22-25 and usually resolves with conservative management alone24-20. It is the most common cause of epiphora in infants ${ }^{1,2} 70 \%$ of neonates present with congenital nasolacrimal duct obstructions at delivery ${ }^{3}$ with only $6-20 \%$ being symptomatic ${ }^{4,5}$ as the obstruction usually resolves before lacrimal secretion begins. ${ }^{6}$ The common approach in the management of this condition is lacrimal massage and observation with or without topical antibiotic treatment as most cases of nasolacrimal duct obstruction resolve without surgery. ${ }^{7-11}$ Another option is an immediate office probing approach with topical anaesthesia and restraint and this was not found to be superior to observation and massage. ${ }^{12}$ The assessment of pediatric epiphora involves looking for a high tear meniscus, recurrent mucopurulent discharge and applying pressure to the lacrimal sac contents by pressure to reflex the contents. ${ }^{6,13}$ Other conditions which may present with epiphora need to be excluded including epiblepharon, congenital entropion, congenital glaucoma, keratitis and uveitis. ${ }^{5}$ The fluorescent dye disappearance test is a non invasive test that can confirm nasolacrimal duct obstruction with $90 \%$ sensitivity 8 . Down's syndrome and craniofacial malformations may be associated with a higher prevalence of congenital nasolacrimal duct obstruction which can be confirmed with imaging. ${ }^{9}$

$80 \%$ of patients have spontaneous resolution of their congenital nasolacrimal duct obstruction. ${ }^{10}$ Bilateral symptoms present in $33 \%$ of patients. ${ }^{14}$ Lacrimal sac massage has long been used to increase the hydrostatic pressure to rupture the any nasolacrimal duct membranous obstruction. ${ }^{10,11}$ Lacrimal sac massage has been shown to be more effective than simple massage or nor massage at all in relieving nasolacrimal duct obstruction. ${ }^{12}$ Success rates of early probing are similar to those of conservative management. ${ }^{12}$ Probing can also result in false passages. ${ }^{15}$ Spontaneous resolution of congenital nasolacrimal duct obstruction can occur after 13 months of age ${ }^{16,17}$ in up to $79 \%$. Spontaneous resolution has also been reported unto 48 months of age. ${ }^{17}$ There is a variation in practice on when to probe with initial suggestions being at less than 13 months and evidence now showing no variation in probing success up to 36 months. ${ }^{7}$ Should an initial probing fail with fluorescent in the nose confirmed in the nose, inferior turbinate fracture may be considered16 to increase the space in the nasal cavity with a success rate of $83 \%$. Silicone tubing may be indicated in cases of repeated unsuccessful probing or where there is a focal blockage. ${ }^{15,18}$ Dacrocystorhinostomy is a procedure of last resort where conservative management, probing, intubation and dilatation have been unsuccessful. It is also indicated in cases 
of bony obstruction; dacryocystitis or dacryocystocele18-20. The success of pediatric external DCR has been quoted to be $88-96 \%$ and is comparable to endonasal DCR at $82-92 \% 21$. There appears to be a variation in practice in the management of congenital nasolacrimal cut obstruction and so this study aimed to look at current practice in England and the United Kingdom amongst oculoplastic surgeons.

\section{Methods}

A survey was sent out to 130 Oculoplastic surgeons in March 2017 with the 10 closed answer questions Appendix 1 in March 2017 via email. The hospital episode statistics of England from the period of 2012 -2016 were looks at for admissions under the C25 and C27 procedure codes which covered dacryocystorhinostomy procedures and probing procedures respectively Appendix 2. The total number of admissions for the coded admissions was looked at including following age groups: less than 1 year, 1-4 year 5-9 year 10-14 years, 15 years, 16 years, 17 years, 18 years.

\section{Results}

The total number of coded procedures for C27.1 Drainage of nasolacrimal duct, C27.2 Dilation of nasolacrimal duct, C27.3 Irrigation of nasolacrimal duct, C27.5 Probing of nasolacrimal duct NEC, C27.8 Other specified operations on nasolacrimal duct, C27.9 Unspecified operations on nasolacrimal duct were combined to include all nasolacrimal ducts procedures performed. The majority of cases occurred in the 1-4 age group with a mean of 1607 procedures performed over the 2012-2016 period. 44 procedures were performed in the less than 1 year age group which is typically considered the age of conservative management. This was compared to the survey question 1-at what age do you stop conservative management and consider syringing and probing of a child. The results were consistent with current evidence as most would consider intervention at 1 year with 16 responses selecting this age. No oculoplastic surgeon would consider intervention at less than 1 year and over 3 years of age. Question 2-up to what age would you consider syringing and probing showed that the majority would consider a procedure at any age of presentation. Question 3-When would you consider the insertion of tubes with a syringing and probing identified that most would consider it at the second syringing and probing, consistent with the current evidence. Few would consider it as athird procedure or not to use tubes at all. With question 4 - After how many syringing and probings would you consider a dacrocystorhinostomy the majority would consider the procedure after 2 syringing and probings and a small numbers would consider it after more than 4 procedures. ${ }^{19-20}$

The total number of coded procedures for
C25.1 Canaliculodacryocystorhinostomy, Conjunctivodacryocystorhinostomy C25.3 Dacryocystorhinostomy and insertion of tube HFQ, C25.4 Dacrycystorhinostomy NE, C25.8 Other specified connection between lacrimal apparatus and nose, C25.9 Unspecified connection between lacrimal apparatus and nose were combined to include all surgical lacrimal anastomotic procedures performed that would be consistent with dacryocytorhinostomy. The majority of cases were performed in the age 1-4 age groups with a mean of 57 procedures performed over the 2012-2016 period. A mean of 1 procedure was carried out at the age of less than 1 year and the majority of cases were performed in the 1-15 age groups. C25.5 Revision of anastomosis between lacrimal apparatus and nose was look at separately. ${ }^{21-25}$ Although the numbers were low the highest number of cases was performed in the age 1-9 age group. The survey question 5-What is the minimum age that you would consider a pediatric endonasal dacryocystorhinostomy found the majority would consider endonasal DCR in children with a slight majority considering such a procedure at the 2 years age group. A significant minority would not consider endonasal DCR in children. Question 6-What is the minimum age of a child that you would consider an external dacryocystorhinostomy found that few would consider external dacryocystorhinostomy in children with the majority considering the procedure at the age of 3-4 years. Question 7-What is your preferred approach for a first pediatric dacryocystorhinostomy showed the majority would consider external dacryocystorhinostomy and not endonasal. Questions 8 and 9 looked at revision dacryoscystorhinostomy surgery. Questions 8-If a child has had a failed endonasal dacryocystorhinostomy and requires a second dacryocystorhinosotmy, what is your preferred approach the majority would consider an external dacryocystorhinosotmy as a second procedure. Question 9-If a child has had a failed external dacryocystorhinosotmy and requires a second dacryocystorhinostomy what if your preferred approach the majority would prefer an external approach. Overall an external approach was the most preferred for revision surgery.

\section{Discussion}

Overall conservative management is considered unto the age of 2 years with some oculoplastic surgeons now considering conservative management up to the age of 3 years. The most common age group for syringing and probing was the 1-4 year age group with the majority of procedures performed in the 0-14 age group. Dacrycystorhinostmy is most commonly considered at the age of 2 or more years with the majority performed in the 1-4 year age group. A significant number of surgeons would now consider endonasal dacryocystorhinostomy for primary and revision surgery although the preference is still for an external approach. There is a suggestion that the 0-9 age group may have a higher number of revision procedures although the numbers are small and so to draw this conclusion may be inaccurate..$^{25-32}$

\section{Acknowledgments}

None.

\section{Conflicts of interest}

Author declares that there is no conflict of interest.

\section{References}

1. Young JD, MacEwen CJ. Managing congenital lacrimal obstruction in general practice. BMJ. 1997;315(7103):293-296.

2. Kapadia MK, Freitag SK, Woog JJ. Evaluation and management of congenital nasolacrimal duct obstruction. Otolaryngol Clin North Am. 2006;39(5):959-977.

3. Cassady JV. Developmental anatomy of nasolacrimal duct. Arch Ophthalmol. 1952;47(2):141-158.

4. Guerary D, Kendig EL. Congenital impotency of the nasolacrimal duct. Arch Ophthalmol. 1950;36(2):212.

5. Cassady JV. Dacryocystitis of infancy. Am J Ophthalmol. 1948;31:773780.

6. Pediatric Eye Disease Investigator Group, Repka MX, Chandler DL. Primary treatment of nasolacrimal duct obstruction with probing in children younger than 4 years. Ophthalmology. 2008;115(3):577-584. 
7. Nelson LB, Calhoun JH, Menduke H. Medical management of congenital nasolacrimal duct obstruction. Pediatrics. 1985;76(2): 172-175.

8. Paul TO. Medical management of congenital nasolacrimal duct obstruction. J Pediatr Ophthalmol Strabismus. 1985;22(2):68-70.

9. Pediatric Eye Disease Investigator Group. Resolution of congenital nasolacrimal duct obstruction with nonsurgical management. Arch Ophthalmol. 2012;130(6):730-734.

10. Kushner BJ. Congenital nasolacrimal system obstruction. Arch Ophthalmol. 1982;;100(4):597-600.

11. Nucci P, Capoferri C, Alfarano R, et al. Conservative management of congenital nasolacrimal duct obstruction. J Pediatr Ophthalmol Strabismus. 1989;26(1):39-43.

12. Lee KA, Chandler DL, Repka MX, et al. A comparison of treatment approaches for bilateral congenital nasolacrimal duct obstruction. Am J Ophthalmol. 2013;156(5):1045-1050.

13. Ffooks OO. Dacryocystitis in infancy. Br J Ophthalmol. 1962;46(7):422434.

14. Paul TO, Shepherd R. Congenital nasolacrimal duct obstruction: natural history and the timing of optimal intervention. J Pediatr Ophthalmol Strabismus. 1994;31(6):362-367.

15. Olver J. Paediatric lacrimal surgery. Colour Atlas of Lacrimal Surgery. Oxford: Butterworth-Heinemann; 2002. p. 69-89.

16. Young JD, MacEwen CJ, Ogston SA. Congenital nasolacrimal duct obstruction in the second year of life: a multicentre trial of management. Eye. 1996;10(Pt 4):485-491.

17. Schellini SA, Capanema S, Ribeiro F, et al. Spontaneous resolution in congenital nasolacrimal obstruction after 12 months. Semin Ophthalmol. 2007;22(2):71-74.

18. Dortzbach RK, France TD, Kushner B, et al. Silicone intubation for obstruction of the nasolacrimal duct in children. Am J Ophthalmol. 1982;94(5):585-590.

19. MacEwen CJ, Young JD. The fluorescein disappearance test (FDT): an evaluation of its use in infants. J Pediatr Ophthalmol Strabismus. 1991;28(6):302-305.
20. Kakizaki H, Takahashi T, Kinoshita S, et al. The rate of symptomatic improvement of congenital nasolacrimal duct obstruction in Japanese infants treated with conservative management during the first year of age. Clin Ophthalmol. 2008;2(2):291-294.

21. Crigler LW. The treatment of congenital dacryocystitis. JAMA. $1923 ; 81: 23-24$.

22. Kushner BJ. Congenital nasolacrimal system obstruction. Arch Ophthalmol. 1982;100:597-600.

23. MacEwen CJ, Young JDH, Barras CW, et al. Value of nasal endoscopy and probing in the diagnosis and management of children with congenital epiphora. Br J Ophthalmol. 2001;85(3):314-318.

24. VanderVeen DK, Jones DT, Tan H, et al. Endoscopic dacryocystorhinostomy in children. J AAPOS. 2001;5(3):143-147.

25. Leibovitch I, Selva D, Tsirbas A, et al. Paediatric endoscopic endonasal dacryocystorhinostomy in congenital nasolacrimal duct obstruction. Graefes Arch Clin Exp Ophthalmol. 2006;244(10):1250-1254.

26. Yazici B,Akova B. Simultaneous bilateral external dacrocystorhinostomy. Acta Ophthalmol Scand. 2007;85(6):667-670.

27. Takashi Y, Kakizaki H, Chan WO, et al. Management of congenital nasolacrimal duct obstruction. Acta Ophthalmologica. 2010;88(5):506-513.

28. Guerry D, Kendig EL. Congenital impatency of the nasolacrimal duct. Arch Ophthalmol. 1948;39(2):193-204.

29. Noda S, Hayasaka S, Setogawa T. Congenital nasolacrimal duct obstruction in Japanese infants: its incidence and treatment with massage. J Pediatr Ophthalmol Strabismus. 1991;28(1):20-22.

30. MacEwen CJ, Young JD. Epiphora during the first year of life. Eye (Lond). 1991;5(Pt 5):596-600.

31. Price HW. Dacryostenosis. J Pediatr. 1947;30(3):302-305.

32. Petersen RA, Robb RM. The natural course of congenital obstruction of the nasolacrimal duct. $J$ Pediatr Ophthalmol Strabismus. 1978;15(4):246-250. 